\title{
Communications
}

\section{The Constituent Variables of Mind Share}

\author{
Hui Hsin Huang \\ Department of Business Administration, Aletheia University, New Taipei, Taiwan
}

Email address:

hoyasophia@gmail.com

\section{To cite this article:}

Hui Hsin Huang. The Constituent Variables of Mind Share. Communications. Vol. 6, No. 2, 2018, pp. 34-38. doi: 10.11648/j.com.20180602.12

Received: February 1, 2018; Accepted: February 16, 2018; Published: March 16, 2018

\begin{abstract}
This paper extents the content of Mind share construction to explore antecedent of confidence and resistance and their relationships. The models of these two variables are proposed and which include customer's information of direct experiment, experience of successful resisting competitor persuasion and the connection knowledge with target product or brand. The sequences process (interactions) between confidence and resistance are also discussed. Finally, the empirical data ofsharing economic are used to test the time-series regression. The conclusion of management application is made.
\end{abstract}

Keywords: Mind Share, Confidence, Resistance

\section{Introduction}

Customers' loyalty is one of the important sources of company competitiveness. It also helps in the device of the marketing strategies and plans (Lam et al, 2004). There are many previous research discuss the loyalty topic includes the influence of customer's satisfaction to loyalty, the antecedent factors of loyalty and their relationships.

According to Oliver (1992) demonstration, satisfy is not necessary leaded to loyalty. Thus Huang (2014) integrates psychological and behavioral concepts to propose a model of consumer loyalty to examine customer's attitudinaland behavioral loyalty. The model employs customer confidence as a moderating variable and resistance as a dependent variable. She found that confidence can negatively moderate the influence of attitudinal loyalty on behavioral loyalty. When confidence is high, higher degrees of attitudinal loyalty are related to lower behavioral loyalty. In addition, confident customers who are familiar with a product tend show less behavioral loyalty by engaging in variety-see king behavior. Her research also found that behavioral loyalty enhances the ability to resist competing brands in order to maintain cognitive consistency.

Based on Huang (2014), the Mind share concept is constructed by customer's confidence toward the brand and their resistance to other competitors and is proposed to portray the quality of customers' loyalty. Thus, the higher the Mind Shares that consumer have possessed for a brand commands, the higher the certainty of the consumers' loyalty. In other words, these consumers have stronger confidence toward this brand and are more able to resist the persuasion from other brands (including advertising, promotions).

Mind share is used to calculate the loyalty quality in four different mobile telecommunications companies (Huang, 2014). It found that the larger the Mind share that a company commands, the stronger the consumer loyalty. In the mind of these consumers, the higher the confidence in the company, the stronger their resistance to persuasion by other company. As a result, Mind share reflects consumer loyalty in a psychological sense, which differs from the usual measure by market share, which reveals only sales fluctuations in the market.

Although Mind share is applicate in the industry, there is lack of deeply discussion of the antecedent variables which consist or influence of confidence and resistance. There is also less extend research to pay attention on the relations between confidence and resistance. This paper proposes a quantitative model in which not only the impact factors of confidence and resistance are included but also the enhanced relationships between these two variables are explored.

This research is consist with five parts. First, the literature review of confidence and resistance are demonstrated. It includes their antecedent variables and the relationships between each other. Secondly, the quantitative model is proposed based on the literature review. The antecedent variables and relationships between confidence and resistance are considered in the model. Thirdly, the empirical data is conduct to estimate the parameters of model and make model validation. Fourthly, the results of parameters estimation and Root-mean-square deviation (RMSD) calculation are shown. 
Finally, the conclusion is made.

\section{Literature Review}

In this section, the theory background of confidence and resistance which are consisting of Mind Share are introducted.

\subsection{Confidence Research and Its Antecedents}

Confidence is the extent to which the buyer believes that he can estimate the net payoff which is the reward from buying a given brand (Bennett \& Harrell, 1975). Confidence plays a major role in the buyer behavior system and to be positively related to intention. If the buyers are segmented on the basis of their confidence in their beliefs will perform better for those who are high in that confidence than for those who are low in confidence (Bennett \& Harrell, 1975).

The previous studies of confidence mostly focus on the role of confidence as a predicator of attitude and behavior (Fazio \& Zanna, 1978). In the studies of consumer persuasion (Petty, Brinol \& Tormala, 2002), confidence is examined in expectations as a moderating variable that influences the relationships established in the disconfirmation - of expectations model (Spreng \& Page, 2001). These studies all mention information as an antecedent that affects confidence. These include information volume, information consistency and information credibility (Smith \& Swinyard, 1988). Berger \& Mitchell (1989) find that the repeated exposures to consistent information and the decision processes associated with perception of the brand can enhance consumers' confidence (Disck \& Basu, 1994).

To examine the role of confidence in attitude and its relationship with behavior from the information perspective, it is found that when there is sufficient information to assist consumers to evaluate product attributes so as to reduce their uncertainty in purchase decision making, their confidence will increase and as a result, the link between attitude to behavior intention will be strengthened (Fazio \& Zanna, 1978; Laroche , Kim, \& Zhou, 1996; Beneett \& Harrell, 1975; Zuwerink \& Devine, 1996; Pomerantz, Chaiken \& Tordesillas, 1995). In other words, if the risks associated with uncertainties borne by consumers in their purchase decisions can be reduced, consumers will increase their confidence (Bennett \& Harrell, 1975). For example, if the sources of product information come respectively from advertisements and direct experience of consumers, the former will create a lower acceptance and higher cognitive resistance for consumers. This higher cognitive resistance will result in a potential reduction of belief strength, which links with the perceived product attributes (Smith \& Swinyard, 1988). Also, direct experience will enhance the acceptance of information and make consumers' beliefs firmer, and thus it, affects their purchase decisions. Thus, information is considered as one factor to influence confidence.

\subsection{Resistance Research and Its Antecedents}

The term "resistance" first appears in persuasive communications mentioned by Hovland et al. (1953). Resistance occurs in the face of persuasion that aims to change attitudes. Resistance usually occurs when individuals experience unfavorable thoughts through distorting the original information or downgrading the reliability of information sources. Research on resistance is also a regular topic in psychology and it includes the effects of personal motivations, self-involvements, importance of attitudes, and the impacts of personal emotions toward resistance against information (Zuwerink \& Devine, 1996).

According to the past studies, as long as consumers can successfully resist powerful persuasion, they become more certain of their original belief (Tormala \& Petty, 2002). Resistance deepens loyalty and assures loyalty. It is a process to defend a personal attitude. By supporting this original attitude, an individual can selectively avoid the information inconsistent with his original attitude or avoid negative emotions. By slandering the message of persuader or contributing the persuasive message to negative emotions, an individual becomes more certain of his attitude. Thus the process in which an individual resists the attacks of persuasions in fact further confirms his original attitude (Tormala \& Petty, 2004). In other words, the previous exposure to the attacks of persuasions enhances the immunity to future attacks. This process can also be explained with meta-cognition. The cognition of an individual is subject to the influence of his own perceptions. When people resist persuasions, they sense their own resistance and infer it to the relevant attitude.

Tormala \& Petty (2004) also mention that this resistance process varies in accordance with the strength of persuasive messages. When an individual resists a strong persuasive message, his original attitude becomes more established. However, if an individual senses that the persuasive message is weak, the successful resistance does not affect his confirmation of the original attitude. Thus, the experience of successful resisting competitor persuasion is considered as a factor about information in the resistance model.

Similar to confidence, knowledge is also an important factor in the path that links attitude with resistance. When an individual has more information connections, he becomes more empowered to resist persuasion (Pomerantz, Chaiken, \& Tordesillas, 1995). The literature regarding confidence mentions that the more information an individual collects, the more confident their attitude becomes. In a similar vein, information is also an important variable in the literature dealing with resistance. Thus, both confidence and resistance work side by side. The confidence boosted by information enhances resistance against persuasion from the opposition. Thus, the connection knowledge with target product or brand is considered as a factor in the resistance model.

\subsection{The Relationships Between Confidence and Resistance}

In the literature regarding loyalty, confidence is a cognitive antecedent and resistance is a consequence of customer loyalty in the structure (Dick \& Basu, 1994). In other words, when consumers have confidence in a brand, the link between 
their loyal attitude and behavior gets stronger. Loyalty is expressed in the form of resistance against persuasive messages from competing brands. Accordingly, confidence is the internal antecedent of loyalty and resistance is the external sequence of loyalty.

In the studies on persuasion, confidence and resistance are both in the domain of meta-cognition. Confidence is the judgment on the certainty of one's belief (Fishbein \&Ajzen, 1975; Simth, \& Swinyard, 1988). On the other hand, resistance is formed, in part, due to the experience of being persuaded. It becomes a part of belief knowledge (Friestad \& Wright, 1994; Tormala \& Petty, 2004), and then affects the subsequent resistance and consumer behavior.

From the perspectives of information, confidence and resistance are positively correlated. The more information collected as regards to products, the stronger the confidence and also the stronger the resistance (Pomerantz, Chaiken \& Tordesillas, 1995). When there are two sources of information, such as advertising and direct experience, advertising generates lower acceptance and higher cognitive resistance, which in turn, decreases confidence strength.

From the perspectives of loyalty, confidence and resistance are like two sides of the same coin. In the mind of consumers, confidence is internal and it deals with the brand in question; on the other hand, resistance deals with competitors. As far as loyalty is concerned, confidence in the brand in question is not sufficient. Despite strong loyalty consumers may have, they may still be lured over to other brands under the attraction of tempting persuasive messages or marketing techniques from other brands. Also, consumers may have certain levels of confidence in several brands at the same time. Thus, the immunity against other brands is a prerequisite. In other words, consumers should have confidence in the brand in question and resistance in other brands. It is found that the successful resistance can help to increase higher confidence.

Thus, the antecedent factor of confidence includes the previous experiments of resistance against competitors. Also, the customer's confidence can influence the ability of resistance to competitors. The framework of figure 1 is demonstrated this sequence process.

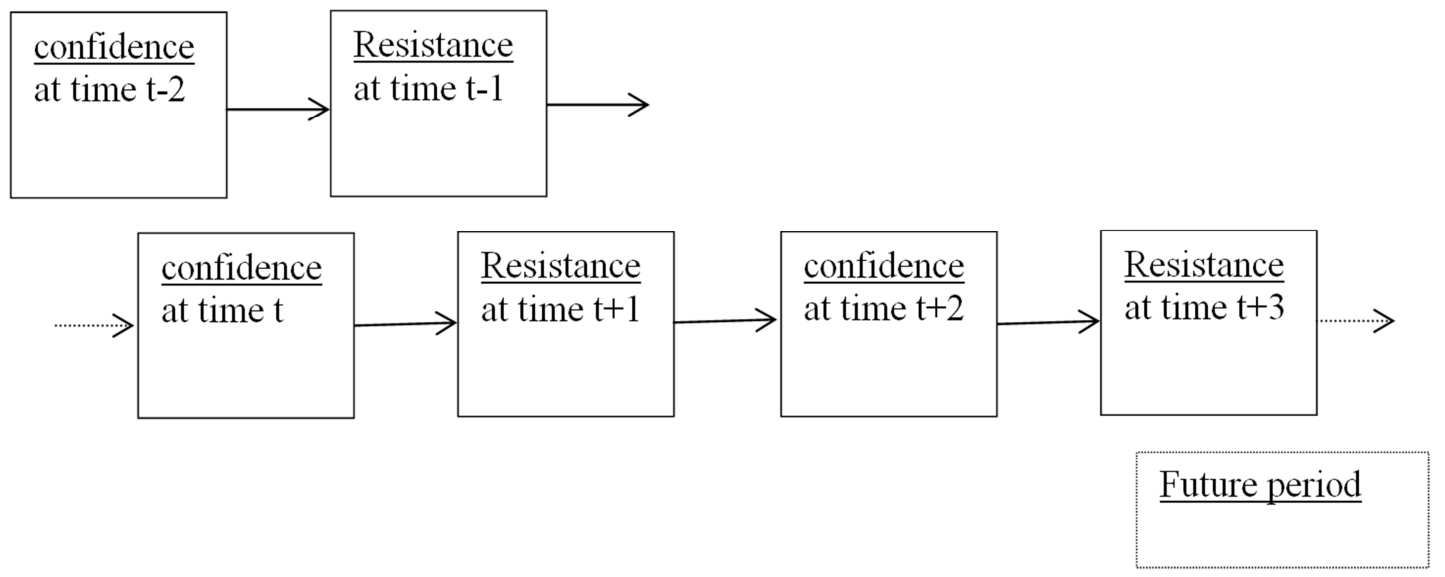

Figure 1. Thesequence process of confidence and resistance.

\section{The Model}

Based on the literature review, the information of target product or brand that customer possess (denote as $I F^{c}$ ) and customer's power of resistance against competitor brand (denote as $R$ ) in the preview time are considered as two impact factors of confidence (denote as $C$ ). $C_{t j}$ is the confidence of $j$-th customer in time $t$. $R_{t j}$ is the resistance of $j$-th customer in time $t$.

$$
C_{t j}=\sum_{i=0}^{n} \alpha_{i j} I F^{c}{ }_{t-i}+\sum_{i=1}^{m} \beta_{i j} R_{t-i}+\pi_{t j}+v_{t j}
$$

In the literature review of resistance, the information of the experience of successful resisting competitor persuasion and the connection knowledge with target product or brand (denote as $I F^{\prime}$ ) is one factor which influence resistance. And another antecedent factor of resistance is the confidence (denote as $C$ ) that customer holds in the previous time when encountering the competitor's persuasion.

$$
R_{t j}=\sum_{k=0}^{n} \delta_{k j} I F^{r}{ }_{t-k}+\sum_{k=1}^{m} \gamma_{k j} C_{t-k}+\pi_{t j}+\omega_{t j}
$$

$\pi_{\mathrm{tj}}$ is the coefficient between confidence and resistance. $v_{t j}$ and $\omega_{t j}$ denotes the customer-specific fixed effects that capture the idiosyncratic characteristics associated with different customers, such as demographic variables (age, education, income) and psychological variable (motivation, involvement). The fixed effects capture all non time varying, unobserved heterogeneity of customers; thus, it can control for unobserved differences across customers.

In these two equations, it can be distinguished between the information in confidence and resistance. In confidence equation, this information is about the direct experience of customer. It is denoted as $I F^{c}$. In resistance equation, the information is about the experience of successful resisting competitor persuasion and the connection knowledge with target product or brand. Thus it is denoted as $I F^{r}$. 


\section{Empirical Data}

Sharing economy is an economic model in which individuals are able to borrow or rent assets owned by someone else. The sharing economy model is most likely to be used when the price of a particular asset is high and the asset is not fully utilized all the time. It also becomes a popular wave in today business market. But some people resist against adapting to share equipment with others because the privacy or feeling uncomfortable with others. Thus this topic is chosen as our empirical application for the model. The data of word of mouth (WOM) and the news reports are used as the source of information. This information is separated into supporting sharing and against sharing. Then, the survey is used to explore the attitude of confidence and resistance.

There are 23721 sequence series data set cross a year in 2017. This sequence data is divided by every month with the response of both confidence and resistance of sharing equipments by customers. This data set is collect by the company which operates the business about a app platform in which the equipments such as bicycle or car is sharing within customers.

This data set is separated into two parts. Firstly, one part is used to estimate the parameters of the proposed model. Secondly, another part is for model validation.

The results of parameters estimation are show in table 1 . According to the data set the $i$ is denoted as the month. The results are standardized $\alpha, \beta, \delta, \gamma$. It shows the increasing trend of month. Higher confidence can case higher resistance in the next time period. In the confidence state, the information of target product (denote as $I F^{c}$ ) and customer's power of resistance against competitor brand positively influence confidence. In the resistance state, the information of the experience of successful resisting competitor persuasion and the connection knowledge with target product or brand (denote as $I F^{r}$ ) positively influence resistance. And the confidence (denote as $C$ ) that customer holds in the previous time when encountering the competitor's persuasion also shows positive impact on resistance.

Table 1. The results of parameters estimation in the proposed model.

\begin{tabular}{lllll}
\hline $\mathbf{i}$ & $\boldsymbol{\alpha}$ & $\boldsymbol{\beta}$ & $\boldsymbol{\delta}$ & $\boldsymbol{\gamma}$ \\
\hline 1 & 0.483 & 0.668 & 0.657 & 0.527 \\
2 & 0.502 & 0.677 & 0.685 & 0.572 \\
3 & 0.501 & 0.679 & 0.688 & 0.601 \\
4 & 0.600 & 0.678 & 0.701 & 0.621 \\
5 & 0.610 & 0.679 & 0.711 & 0.681 \\
6 & 0.612 & 0.701 & 0.721 & 0.691 \\
7 & 0.653 & 0.721 & 0.725 & 0.695 \\
8 & 0.667 & 0.725 & 0.733 & 0.698 \\
9 & 0.698 & 0.729 & 0.732 & 0.700 \\
10 & 0.698 & 0.733 & 0.752 & 0.711 \\
11 & 0.700 & 0.745 & 0.758 & 0.721 \\
12 & 0.715 & 0.765 & 0.766 & 0.722 \\
\hline
\end{tabular}

Then, based on the results of parameters estimation, the second part of data is put in the model to make validation. The Root-mean-square deviation (RMSD) is used to evaluation the good- fitness of model. RMSD is 0.875 which is near to 1 . It shows acceptable fitness of our proposed model.

\section{Conclusion}

This research uses sequence linear model to portray dynamic process of customer's confidence and resistance. Because confidence of some information or brand and resistance of competitor persuasion is like a circle chain in which more confidence with the information can increase the probability of successful against the competitor information. The confidence that customer holds in the previous time when encountering the competitor's persuasion also shows positive impact on resistance. And customer have more power of resistance against competitor brand then will also increase their confidence of target brand.

This research also convinces that customer possess much number of the information of target product or brand will case more confidence among target product. Customers have more experience of successful resisting competitor persuasion and the connection knowledge with target product or brand will increase their ability of resistance against competitor brands. The information or experience is a key factor both in confidence and resistance.

In the future, another model such as logistic model or nonlinear model can be try to discuss the relationships between confidence and resistance. Moreover, more antecedent variables or more detail of the impact factors of confidence and resistance can be discussed. The researchers can also explore more deeply about how Mind share works when the constructor of confidence and resistance are influenced by their antecedent variables.

\section{References}

[1] Bearden, O. W., Hardesty, M. D. \& Randall, L. R. (2001). Consumer self-confidence: Refinements in conceptualization and measurement. Journal of Consumer Research, 28 (1), 121-134.

[2] Bennett, P. D. \& Harrell, G. D. (1975). The role of confidence in understanding and predicting buyers' attitudes and purchase intentions. Journal of Consumer Research, 2 (2), 110-117.

[3] Bennett, P. D. \& Harrell, G. D. (1975). The role of confidence in understanding and predicting buyers' attitudes and purchase intentions. Journal of Consumer Research, 2 (2), 110-117.

[4] Berger, E. I. \& Mitchell, A. A. (1989). The effect of advertising on attitude accessibility attitude, confidence, and the attitude-behavior relationship. Journal of Consumer Research, 16 (3), 269-279.

[5] Dick, A. S. \& Basu, K. (1994). Customer loyalty: toward an integrated conceptual framework. Academy of Marketing Science, 22 (2), 99-114.

[6] Fazio, R. H. \& Zanna, M. P. (1978). On the predictive validity of attitudes: The roles of direct experience and confidence. Journal of Personality, 46 (2), 228-243.

[7] Fishbein, M. \& Ajzen, I. (1975). Belief, attitude, intention and behavior: An introduction to Theory and Research, Reading. MA: Addison-Wesley. 
[8] Friestad, M. \& Wright, F. P. (1994). The persuasion knowledge model: How people cope with persuasion attempts. Journal of Consumer Research, 21 (1), 1-31.

[9] Hovland, C. I., Janis, I. L. \& Kelly, H. H. (1953). Communication and persuasion. New Haven, CT: Yale University Press.

[10] Huang, H. H. (2014). Construction of Mind Share in Loyalty Concept in Terms of Confidence and Resistance. Marketing Review, 11 (2), pp. 133-154.

[11] Huang, H. H. (2014). Explorative Study on the Concept of Mind Shares: Confidence, Resistance and Loyalty. Expert Journal of Marketing, 2 (1), 15-27.

[12] Huang, H. H. (2014). From Attitudinal Loyalty to Behavioral Loyalty: Construction of Loyalty Model. Pensee, 76 (4), 125-138.

[13] Hui-Hsin, Huang (2015). Using Mind Share Calculation and Fuzzy Concept to Explore Customer's Psychological Pattern. Procedia - Social and Behavioral Sciences, 175 (12) February, 170-175.

[14] Laroche, M., Kim, C. Zhou, L. (1996). Brand familiarity and confidence as determinants of purchase intention: An empirical test in a multiple brand context. Journal of Business Research, 37 (2), 115-121.

[15] Oliva, A. T., Oliver, L. R. \& MacMillan, C. I. (1992). A Catastrophe model for developing service satisfaction strategies. Journal of Marketing, 56 (3), 83-95.
[16] Petty, E. R., Brinol, P. \& Tormala, L. Z. (2002). Thought confidence as a determinant of persuasion: The self-validation hypothesis. Journal of Personality and Social Psychology, 82 (5), 722-741.

[17] Pomerantz, E. M., Chaiken, S. \& Tordesillas, R. S. (1995). Attitude strength and resistance process. Journal of Personality and Social Psychology, 69 (September), 408-419.

[18] Simth, E. R. \& Swinyard, R W. (1988). Cognitive response to advertising and trial belief strength, belief confidence and product curiosity. Journal of Advertising, 17 (3), 3-14.

[19] Spreng, A. R. \& Page, J. T. (2001). The impact of confidence in expectations on consumer satisfaction. Psychology \& Markeitng, 18 (11), 1187-1204.

[20] Tormala, L. Z.\& Petty, E. R. (2002). What doesn't kill me makes me stronger: The effects of resisting persuasion on attitude certainty. Journal of Personality and Social Psychology, 83 (6), 1298-1313.

[21] Tormala, L. Z.\& Petty, E. R. (2004). Source Credibility and Attitude Certainty A Metacognitive Analysis of Resistance to Persuasion. Journal of Consumer Psychology, 14 (4), 427-442.

[22] Zuwerink, J. R. \& Devine, P. G.. (1996). Attitude importance and resistance to persuasion Its not just the thought that counts. Journal of Personality and Social Psychology, 70 (5), 931-944. 